- Emphasises the importance of the role of the dental team in tobacco cessation and shows some continuing barriers faced by the dental team to engage in this activity.

- Shows that most dentists and their teams are very willing to implement tobacco cessation strategies in their practices.

- Highlights the need for more training for the dental team in tobacco cessation and the importance of facilitating the availability of patient education materials.

\title{
Tobacco cessation activities of UK dentists in primary care: Signs of improvement
}

\author{
N. W. Johnson, ${ }^{1}$ J. C. Lowe ${ }^{2}$ and K. A. A. S. Warnakulasuriya ${ }^{3}$
}

Objective To investigate attitudes and opinions of the members of the British Dental Association towards implementing tobacco cessation strategies in dental practices. Design and method Questions about tobacco and tobacco cessation were asked on the September 2002 BDA Omnibus survey. The survey was sent out to a random sample of 1,500 BDA members, excluding retired members, overseas members and students. After two reminder circulations, 870 completed questionnaires were received, giving a response rate of $58 \%$. Results The survey results revealed good awareness amongst respondents of the health risks of tobacco. One fifth of respondents said that patients had asked them for advice on tobacco cessation. The majority (64\%) of respondents stated that they gave advice on tobacco cessation 'fairly regularly' or 'always' (whether asked or not) and $37 \%$ of respondents recommended over-the-counter nicotine replacement therapy. Overall, 68\% of respondents agreed that offering patients advice about tobacco cessation was the duty of every dentist. The most common barriers to a successful tobacco cessation campaign were perceived to be the amount of time required, lack of reimbursement, lack of training, lack of patient education materials and lack of knowledge of available referral resources. Nearly all respondents (92\%) said that their practice was a completely smoke-free environment, and $66 \%$ of respondents had never used tobacco. The majority of respondents displayed patient education materials in their practice waiting/reception areas less than $60 \%$ of the time, and nearly a quarter (23\%) never had them available. The survey revealed that most respondents did not feel particularly well prepared to assist patients in quitting tobacco, but 70\% of respondents said they would be willing to cooperate with a campaign to inform all tobacco using patients about the advantages of tobacco cessation. Respondents felt that leaflets for patients, staff training and posters in the practice would contribute to the success of the campaign. Conclusion Members of the dental team are very willing to implement tobacco cessation strategies in the dental practice. Most dentists feel that promotion of tobacco cessation is an important part of the duty of a dentist, but they feel inadequately prepared to deliver such advice. The major barriers to delivering successful tobacco cessation campaigns are the amount of time required, lack of reimbursement, lack of training, lack of patient education materials and lack of knowledge of available referral resources. The majority of dentists have received no training in tobacco cessation strategies. They feel that staff training and free availability of more patient education materials (leaflets, posters, etc) would help promote the success of such a campaign.

\footnotetext{
$1^{*}$ Founder Dean, School of Dentistry \& Oral Health, Griffith University, Gold Coast Campus, 9726 Queensland, Australia; ${ }^{2}$ Policy Development Officer, British Dental Association, Floor 4, 2 Caspian Point, Cardiff Bay, Cardiff, CF10 4DQ; ${ }^{3}$ Professor of Oral Medicine, GKT Dental Institute and WHO Collaborating Centre for Oral Cancer and Precancer, King's College London

*Correspondence to: Professor Newell Johnson

Email:n.johnson@griffith.edu.au
}

\section{Refereed Paper}

Accepted 13 Sep 05

doi: $10.1038 /$ sj.bdj.4813148

(๑) British Dental Journal 2006; 200: 85-89

\section{INTRODUCTION}

'Dentists practising in the twenty-first century cannot ignore patients' tobacco use.' - Rhys B. Jones ${ }^{1}$

Tobacco is a serious public health concern in the UK and worldwide. Around 13 million adults in the UK smoke ${ }^{2}$ and many adults from ethnic minority groups chew smokeless tobacco and/or areca nut (pan). ${ }^{3}$ Smoking or chewing tobacco can seriously affect oral, as well as general, health ${ }^{4}$ and tobacco consumption is one of the main causes of oral cancer, a serious and growing worldwide problem. ${ }^{5,6}$ Over $90 \%$ of oral cancer patients in the UK have used tobacco $^{7}$ and more than $90 \%$ of head and neck (including oral) cancers worldwide can be attributed to the combined effects of tobacco use, heavy alcohol consumption and poor diet. ${ }^{8}$ All oral health clinicians should routinely examine the soft tissues of their patients' mouths for signs of mucosal disease (including oral cancer 


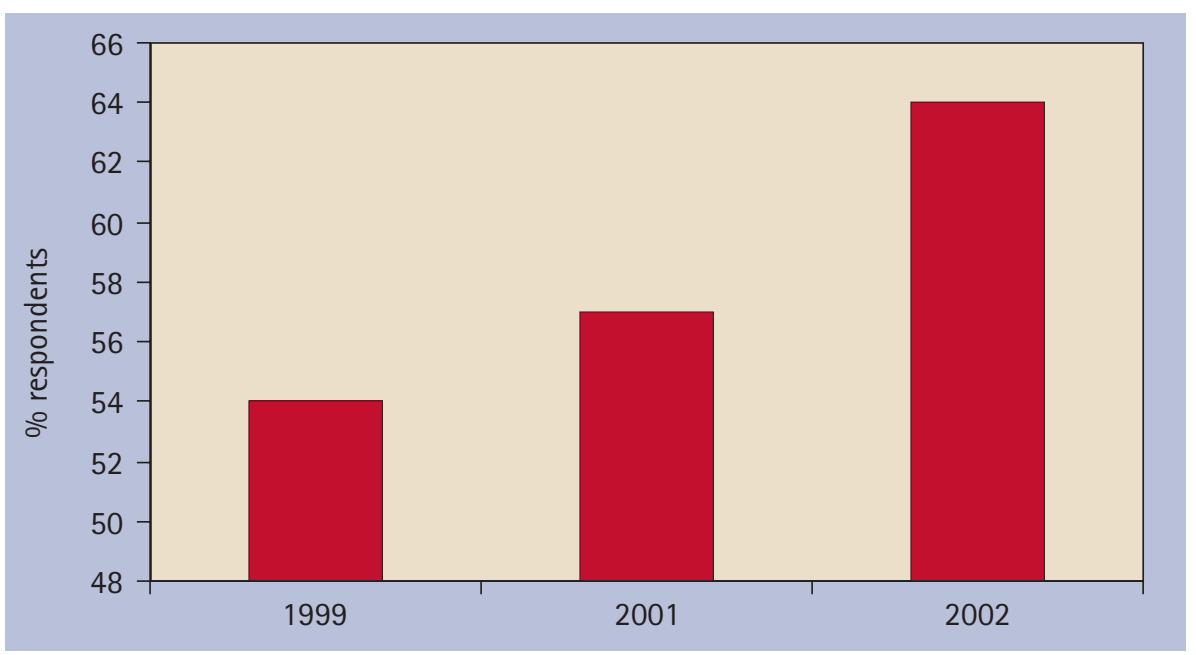

Fig. 1 Percentage giving tobacco cessation advice fairly regularly or always

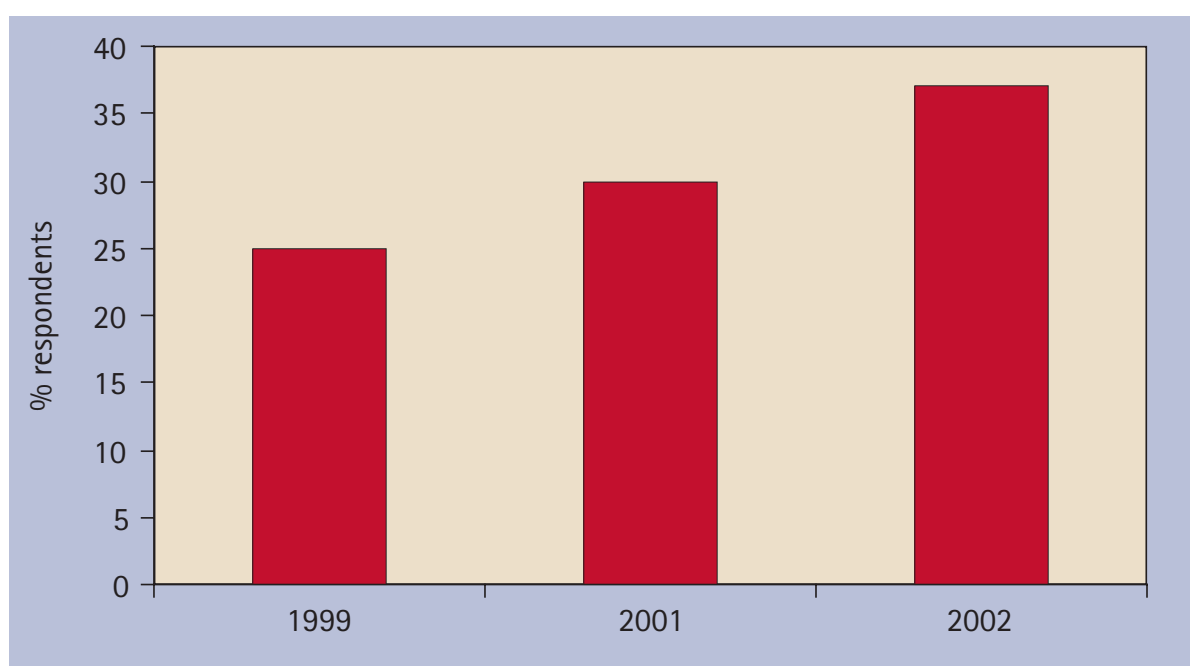

Fig. 2 Percentage recommending over the counter NRT

and potentially malignant lesions) and arrange appropriate referrals. ${ }^{6,9}$

Smoking causes around 120,000 premature deaths per year in the UK. ${ }^{2}$ It is the largest single preventable cause of death in the country ${ }^{2}$ and treatment of smokingrelated diseases costs the NHS about $£ 1,500$ million per year. ${ }^{2,10}$ Dentists have a 'potential target' while carrying out work on a patient, and as such have an excellent opportunity to advise patients and encourage tobacco cessation. Dentists are the only healthcare professionals who frequently see 'healthy' patients (according to the 1998 Adult Dental Health Survey, ${ }^{11}$ 59\% of dentate adults in the UK have regular dental health check-ups) and therefore are in a very good position to identify possible tobacco-related problems early. In December 1998 the Government published a White Paper on tobacco, in which was set out a comprehensive agenda for action on tobacco use. ${ }^{12}$ The links between tobacco and oral health provide an ideal opportunity for the dental team to become involved in tobacco cessation strategies. Tobacco use is as much an issue for dentists as it is for other healthcare professionals ${ }^{13,14}$ but, if dental patients are to benefit from tobacco cessation interventions, dentists need to be clear about their roles nationally, locally and within the team in their own practice. ${ }^{15,16}$ Following the Government White Paper, extensive guidelines for health professionals on the implementation of effective $^{17}$ and cost effective ${ }^{10}$ smoking cessation strategies have been published and summarised. ${ }^{18}$ These include guidelines specifically aimed at the dental team, for example the recently published Helping smokers stop - a guide for the dental team ${ }^{19}$ (a joint publication produced by the British Dental Association and the Health Development Agency). If dentists truly want to care for the oral health of their patients, they must take tobacco cessation seriously. ${ }^{20}$ As detailed in the recent White Paper Choosing Health: making healthier choices easier, ${ }^{21}$ tobacco cessation is currently a high priority for the Government and all health professionals (including dentists) are being encouraged to help patients to quit tobacco.

Many dentists in the $\mathrm{UK}^{22,23}$ and in other European Union countries ${ }^{24}$ have a positive attitude towards tobacco
Table 1 Would you be more likely to recommend NRT if you could prescribe it on the NHS?

\begin{tabular}{lll}
\hline & $\begin{array}{l}\text { Yes } \\
\%\end{array}$ & $\begin{array}{l}\text { No } \\
\%\end{array}$ \\
\hline Overall & 50 & 50 \\
\hline North & 53 & 47 \\
South & 46 & 54 \\
\hline Male & 48 & 52 \\
Female & 53 & 47 \\
\hline Under 35 years & 55 & 45 \\
35-50 years & 49 & 51 \\
Over 50 years & 48 & 52 \\
\hline GDPs & 51 & 49 \\
Salaried dentists & 43 & 57 \\
\hline Single-handed practice & 47 & 53 \\
Group practice & 51 & 49 \\
\hline 75\% or more NHS & 54 & 46 \\
74\% or less NHS & 47 & 53 \\
\hline
\end{tabular}

cessation strategies and feel that dentists have a role to play in helping their patients give up tobacco. However, unfortunately they lack confidence in their effectiveness to promote tobacco cessation and feel that they need more training and resources. Interestingly, a survey of dental patients in the US ${ }^{25}$ showed that many patients also believe that dentists should be proactive in encouraging tobacco cessation. A survey conducted in $12 \mathrm{EU}$ countries in 1998 revealed that the major barriers to the incorporation of tobacco cessation activities in dental practices throughout Europe were expected patient resistance, lack of time, lack of reimbursement mechanisms and lack of readily accessible patient education materials. ${ }^{24}$ The survey showed that over 50\% of EU dentists would be willing to participate in a tobacco cessation campaign for all patients, although only onethird of dentists enquired routinely about patient tobacco use. Reassuringly, twothirds of EU dentists gave advice about the harmful effects of tobacco to patients with tobacco-related oral diseases. However, it could be argued that the quality of this service is variable.

This paper reports the findings of a survey conducted by the BDA in September 2002 to investigate attitudes and opinions of dentists towards implementing tobacco cessation strategies.

\section{SURVEY}

Questions were asked on the September 2002 BDA Omnibus survey. Until January 2005, BDA Omnibus surveys were carried out twice a year and included questions for outside agencies as well as BDA-centred questions. The BDA currently carries out four Omnibus surveys per year. The September 2002 survey included a section on tobacco. Some of the questions were identical to those asked on previous Omnibus surveys (conducted in 1999 and 2001), ${ }^{26,27}$ to allow comparison. The 
remainder of the questions were worded in the same way as those on the questionnaire sent out to all EU countries in 1998. ${ }^{24}$ The survey was sent to $1,500 \mathrm{BDA}$ members, excluding retired members, overseas members and students. A prepaid envelope was included with the survey and recipients were asked to complete the questionnaire and return it to the BDA. Two reminders were circulated.

The tobacco section of the questionnaire asked questions about:

- The level of association between tobacco and various oral diseases/conditions.

- Tobacco cessation advice and NRT.

- Barriers to implementation of tobacco cessation strategies.

- How prepared dentists felt to deliver tobacco cessation advice.

There were 14 questions in this section of the Omnibus survey. [A copy of the questionnaire is available on request from the authors.] The data were analysed using SPSS version 10.0 .

\section{FINDINGS AND POINTS OF INTEREST}

Of the 1,500 surveys sent out, 870 usable questionnaires were returned, giving a final response rate of 58\%. This response rate is reasonable and is comparable to those achieved in other BDA Omnibus surveys. However, the possibility of nonresponse bias should be borne in mind when interpreting the results. Overall, 77\% of survey respondents were working in general dental practice, 20\% were working in the salaried dental services and the remaining 3\% were either not working or not working in dentistry. Of those working in general dental practice, $20 \%$ were in single-handed practice, and 53\% derived more than three-quarters of their income from NHS work. The north-south split (defined as those living north or south of a Bristol-Wash divide) was roughly equal, with 53\% of respondents from the north and $47 \%$ from the south (respondents from Wales, Northern Ireland and Scotland are included in the northern group). Sixtyseven per cent of respondents were male and 33\% were female. More than half $(54 \%)$ of the survey respondents were aged between 35 and 50 years, with only 18\% aged under 35 and 28\% aged over 50 .

More than 95\% of respondents knew that there was an association between tobacco use and oral cancer, lung cancer, oral leukoplakia, coronary diseases, carcinoma of the larynx and periodontal disease and 94\% knew that tobacco could cause impairment of wound healing. These results show a good awareness of the health risks of tobacco, and are similar to those observed in the EU survey conducted in 1998. ${ }^{24}$ However, $21 \%$ of respondents did not know whether

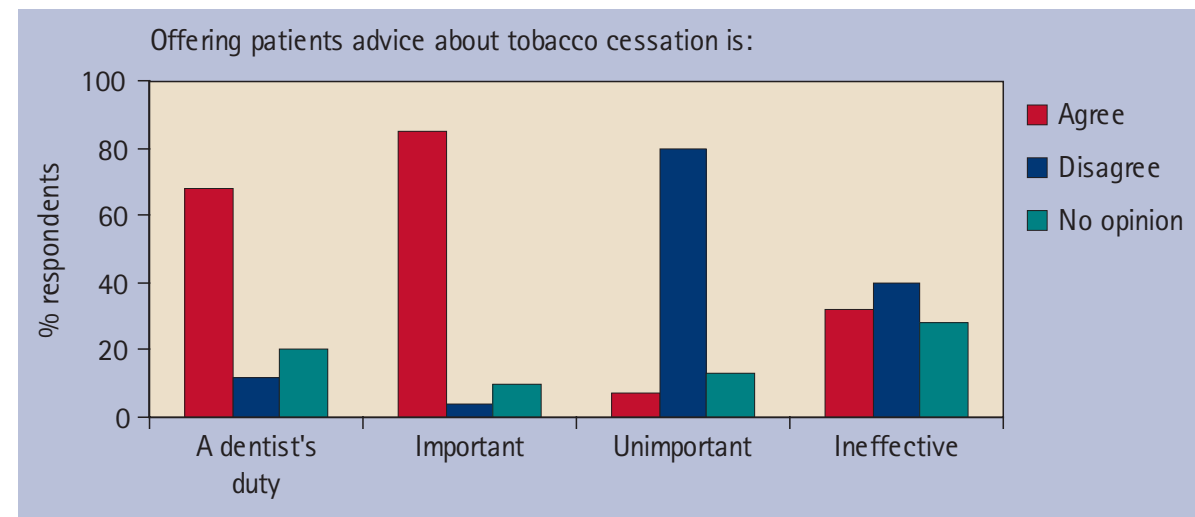

Fig. 3 The role of the dentist in offering patients advice about tobacco cessation

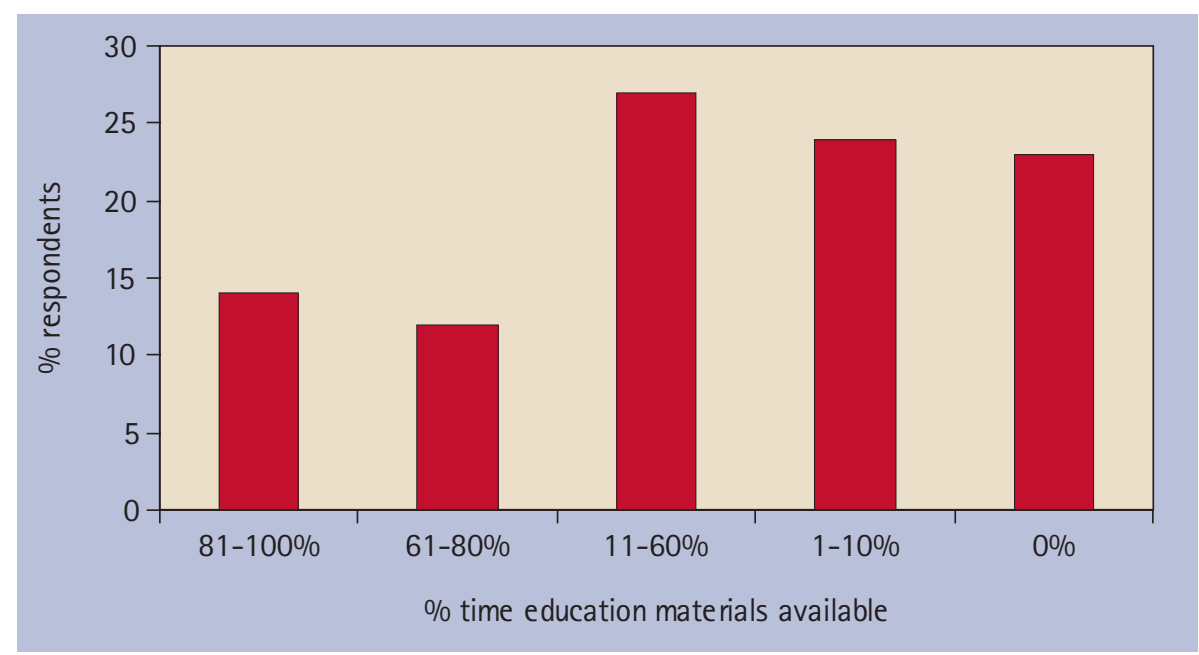

Fig. 4 Availability of education materials in practice reception/waiting area

or not there was an association between tobacco and implant failure (which there is $^{4}$ ) or odontogenic tumours (no known association) and 13\% did not know if there was a link between oral candidiasis and tobacco use (between which a relationship exists $\left.{ }^{4}\right)$. Just over a quarter of respondents (26\%) were of the opinion that there was an association between tobacco and dental caries, but in fact no such relationship has been established for smoked tobacco. ${ }^{4}$ Interestingly, this is the same result as was observed in the EU survey.

One fifth of respondents said that patients asked them for advice on tobacco cessation. This number has not changed a great deal since $1999 .{ }^{26}$ The survey also asked members how often they gave their patients advice on tobacco cessation (whether asked or not). The percentage giving advice 'fairly regularly' or 'always' has increased steadily since 1999 (from $54 \%$ in $1999^{26}$ to $57 \%$ in $2001^{27}$ to $64 \%$ in 2002) as shown in Figure 1. These results are even more reassuring when compared with data from $1991,{ }^{28}$ when only $30 \%$ of UK dentists inquired into patients' tobacco habits and only 30\% of those provided very brief advice about tobacco cessation.

The percentage of respondents recommending over-the-counter nicotine replacement therapy has also increased steadily since 1999 : from $25 \%$ in $1999^{26}$ to $30 \%$ in $2001^{27}$ to $37 \%$ in 2002 (as shown in Fig. 2).

Respondents were asked whether they would be more likely to recommend NRT if they could prescribe it on the NHS. Overall, 50\% thought that this would make it more acceptable for dentists to recommend it, but, as shown in Table 1, there were some interesting variations in the subgroup results: for example 51\% of GDPs would be more likely to recommend NRT if they could prescribe it on the NHS, compared with $43 \%$ of salaried dentists.

The survey asked members whether they agreed or disagreed that offering patients advice about tobacco cessation was:

1. A dentist's duty?

2. Important?

3. Unimportant?

4. Ineffective?

The responses to this question are given in Figure 3. This question was also asked in the EU survey, and the overall results indicated that $68 \%$ of respondents agreed that offering patients advice about tobacco cessation was the duty of every dentist. ${ }^{24}$ As shown in Figure 3, this result is identical to that obtained from the Omnibus survey. 


\begin{tabular}{|c|c|c|c|}
\hline Barriers & $\begin{array}{l}\text { GDPs } \\
\%\end{array}$ & $\begin{array}{l}\text { Salaried } \\
\%\end{array}$ & $\begin{array}{l}\text { Overall } \\
\%\end{array}$ \\
\hline Patient resistance/complaints & 26 & 19 & 25 \\
\hline Amount of time required & 53 & 24 & 47 \\
\hline Lack of reimbursement & 52 & 18 & 46 \\
\hline Resistance by staff & 9 & 10 & 9 \\
\hline Concerns about effectiveness & 24 & 19 & 23 \\
\hline Lack of training in this area & 38 & 33 & 38 \\
\hline Lack of support from management & 27 & 18 & 25 \\
\hline Lack of patient education materials & 38 & 28 & 36 \\
\hline Availability of referral resources & 41 & 27 & 38 \\
\hline Unable to prescribe NRT on the NHS & 28 & 10 & 25 \\
\hline
\end{tabular}

\begin{tabular}{llllll}
\multicolumn{7}{l}{ Table 3 How prepared do you feel to assist patients in quitting tobacco? } \\
\hline & $\begin{array}{l}\text { Very well } \\
\text { prepared } \\
\%\end{array}$ & $\begin{array}{l}\text { Well } \\
\text { prepared } \\
\%\end{array}$ & $\begin{array}{l}\text { Adequately } \\
\text { prepared } \\
\%\end{array}$ & $\begin{array}{l}\text { Not well } \\
\text { prepared } \\
\%\end{array}$ & $\begin{array}{l}\text { Not at all } \\
\text { prepared } \\
\%\end{array}$ \\
\hline Overall & 4 & 7 & 26 & 48 & 15 \\
\hline Under 35 years & 1 & 5 & 22 & 61 & 11 \\
\hline $35-50$ years & 3 & 6 & 27 & 47 & 17 \\
\hline Over 50 years & 8 & 9 & 25 & 44 & 14 \\
\hline
\end{tabular}

Respondents were given a list of possible barriers to incorporating tobacco cessation activities in their practice and asked how often each was a problem. The following were considered to be regular barriers:

- Amount of time required $(47 \%$ of respondents)

- Lack of reimbursement $(46 \%$ of respondents)

- Lack of training in this area $38 \%$ of respondents)

- Lack of patient education materials (36\% of respondents)

- Lack of knowledge of available referral resources (38\% of respondents).

Interestingly, only 25\% regularly found patient resistance a barrier, although in the EU survey this was cited as one of the main problems. ${ }^{24}$ The other main barriers in the EU survey were lack of time, lack of reimbursement mechanisms and lack of readily accessible patient education materials. So, while patient compliance improved between 1998 and 2002, the 2002 survey indicated that dentists wanted more training and better referral resources.

The results indicated that most of the barriers listed were more regularly a problem for GDPs than salaried dentists, as shown in Table 2. For example, more than half (53\%) of GDPs responding to the survey regularly found the amount of time required for delivering tobacco cessation advice a problem, compared with less than a quarter (24\%) of salaried dentists. Lack of reimbursement for tobacco cessation advice was a far greater problem for GDPs: $52 \%$ regularly found this a barrier, compared with only $18 \%$ of salaried dentists. A way forward would be for the PCTs to pay for this service whether a GP or GDP undertakes this activity in primary care.

The results indicated that GDPs found availability of adequate referral resources a greater barrier than salaried dentists (41\% of GDPs regularly found this a problem, compared with $27 \%$ of salaried dentists). This could, however, be due to a lack of knowledge about available local resources. Each PCT now has a specialised smoking cessation service which will accept referrals. Contact details for these services can be found online at www.givingupsmoking.co.uk. In addition, $28 \%$ of GDPs regularly found being unable to prescribe NRT on the NHS a barrier to providing tobacco cessation advice, compared with only $10 \%$ of salaried dentists.

Nearly all respondents (92\%) described their practice as a completely smoke-free environment, and $66 \%$ of respondents had never used tobacco. Interestingly, proportionately more of those working in singlehanded practices used tobacco every day (10\% compared with less than 5\% of dentists in practices with two or more dentists). Also of interest is that $72 \%$ of respondents aged under 35 had never used tobacco, compared with only $57 \%$ of those older than 50. However, there was not very much difference between the numbers in each age group currently using tobacco. The EU results for these questions indicated that overall three-quarters of all respondents had completely smoke-free practices. ${ }^{24}$ However, there was a huge variation between different countries and specific data for the UK were not given. Interestingly, 73\% of UK respondents to
Table 4 Have you received training in tobacco cessation intervention strategies?

\begin{tabular}{lll}
\hline & $\begin{array}{l}\text { Yes } \\
\%\end{array}$ & $\begin{array}{l}\text { No } \\
\%\end{array}$ \\
\hline Overall & 10 & 90 \\
\hline Male & 9 & 91 \\
Female & 13 & 87 \\
\hline GDPs & 9 & 91 \\
Salaried & 15 & 85 \\
\hline Single-handed practice & 7 & 93 \\
Group practice & 9 & 91 \\
\hline $75 \%$ or more NHS & 7 & 93 \\
74\% or less NHS & 11 & 89 \\
\hline
\end{tabular}

the EU survey had never used tobacco, compared with $66 \%$ of respondents to the Omnibus survey.

The survey also asked respondents how often patient education materials on tobacco cessation were available in their practice reception/waiting areas. The responses to this question are shown in Figure 4.

The majority of respondents had patient education materials available less than $60 \%$ of the time, and nearly a quarter (23\%) never had them available. Respondents were also asked how much time, on average, was spent talking about tobacco use with each patient. Overall, 45\% respondents spent between one and two minutes, and $27 \%$ spent less than one minute. There was some variation in the subgroup results for this question, with those in the south, women, salaried dentists and those deriving less than threequarters of their income from NHS work being proportionately more likely to spend a little longer with each patient.

The survey revealed that most respondents did not feel particularly well prepared to assist patients in quitting tobacco. The overall responses and a breakdown by age are shown in Table 3. As can be seen from the table, nearly two-thirds (63\%) of respondents said they felt either "not at all prepared' or 'not well prepared'. The results indicated that $72 \%$ of those aged under 35 felt either not at all or not well prepared, compared with 64\% of those aged 35-50 and $58 \%$ of those aged over 50. This implies that training at undergraduate level on this important public health topic has not improved over the years.

Only 10\% of respondents had received formal training in tobacco cessation intervention strategies: the majority (59\%) of these had received the training through a continuing education programme. As shown in Table 4, proportionately more women, salaried dentists, those working in practices with four or more dentists and respondents with a lower commitment to the NHS had received formal training. Of those who had not received training, the majority (72\%) were either somewhat or very willing to receive training in 
this area. Women were considerably more willing to undergo training (36\% were very willing, compared with 19\% of men), as were younger dentists (31\% of respondents aged under 35 were very willing, compared with $26 \%$ of those aged between 35 and 50 and $18 \%$ of those over 50 ).

Overall, $70 \%$ of respondents said they would be willing to cooperate with a campaign to inform all tobacco using patients about the advantages of tobacco cessation. This is an increase on the overall results from the EU survey, which indicated that only 55\% of respondents were willing to cooperate with a campaign for all tobacco-using patients, although 29\% were willing to cooperate with a campaign for those with tobacco-related oral disease. Respondents were asked to mark which of a list of options would contribute to the success of the campaign. The most popular choices were leaflets for patients (84\% of respondents), staff training (62\%) and posters in the practice (59\%). Over half (52\%) felt that being able to prescribe NRT on the NHS would contribute to the success of the campaign.

Proposed changes to dental prescribing arrangements, due to be implemented in 2006, will allow dentists greater access to the British National Formulary. ${ }^{29}$ This will enable them to prescribe NRT on the NHS and it is hoped that this will encourage dentists to be proactive in promoting tobacco cessation campaigns in their practices. In addition, the Department of Health has recently established a 'Smoking Cessation and Oral Cancer Group' to formalise training for dentists on tobacco cessation and increase awareness of oral cancer within the profession.

It has been shown that the effectiveness of a dentist in providing brief advice on cessation is comparable to a GP in many primary care settings. ${ }^{30}$ Use of all primary healthcare providers in tobacco cessation activities should be facilitated by making pharmacological interventions for smokers easily available through dentists. A demonstration programme ${ }^{31}$ in the South of England that allowed dentists to provide NRT in their practices (through prescriptions written by specialists) recorded a successful cessation rate of $11 \%$, comparable to many GP-led studies. Dentists who wish to update their knowledge on the role they can play in helping patients quit tobacco should consult guidelines which are now available. ${ }^{17,18,32}$

\section{CONCLUSIONS}

In conclusion, the 2002 BDA Omnibus survey showed that, during recent years, there has been a steady improvement in knowledge, attitudes and behaviour of UK dental practitioners towards encouraging patients to give up tobacco. Members of the dental team are very willing to implement tobacco cessation strategies in the dental practice. Very few dentists currently smoke, and most practices are smoke-free environments. Most dentists feel that promotion of tobacco cessation is important and part of the duty of a dentist, but they feel inadequately prepared to deliver such advice. The major barriers to delivering successful tobacco cessation campaigns are the amount of time required, lack of reimbursement, lack of training, lack of patient education materials and availability of referral resources. The majority have received no training in tobacco cessation strategies, and feel that this would help promote the success of such a campaign. In addition, availability of targeted patient education materials - leaflets, posters, etc would be useful.

1. Jones R B. Tobacco or oral health: past progress, impending challenge, J Am Dent Assoc 2000: 131: 1130-1136

2. www.ash.org.uk

3. Zain R B, Ikeda N, Gupta P C et al. Oral mucosal lesions associated with betel quid, areca nut and tobacco chewing habits: consensus from a workshop held in Kuala Lumpur, Malaysia, November 25-27, 1996. J Oral Pathol Med 1999; 28: 1-4

4. Johnson N W, Bain CA. Tobacco and oral disease. EU working group on tobacco and oral health BrDent J2000, 189: 200-206.

5. Johnson N W. Oral cancer. UK: FDI World Dental Press Ltd, 1999

6. Warnakulasuriya S. Global aspects of oral cancer: reported screening programmes and outcomes. CPD Dent 2001:2: 5-8.

7. Cancer Research UK: Cancer Stats. Oral Cancer January 2005.

8. Johnson N W. Tobacco use and oral cancer: a global perspective, J Dent Educ 2001; 65: 328-339.

9. British Dental Association. Opportunistic oral cancer screening - a management strategy for the dental practice. BDA Occasional Paper No. 6, April 2000.
10. Parrott S, Godfrey C, Raw M et al. Guidance for commissioners on the cost effectiveness of smoking cessation interventions. Thorax 1998 53: Suppl 5, Part 2.

11. Office for National Statistics. Adult dental health survey - oral health in the UK 1998. London: The Stationery Office, 2000

12. Department of Health. Smoking kills - a white paper on tobacco. London: The Stationery Office, 1998.

13. Watt R G, Johnson N W, Warnakulasuriya K A. Action on smoking - opportunities for the dental team. BrDent J 2000; 189: 357-360.

14. Watt R G, Daly B, Kay EJ. Prevention. Part 1: smoking cessation advice within the general dental practice. $B$ Dent J 2003; 194: 665-668.

15. Monaghan N. What is the role of dentists in smoking cessation? Br Dent J 2002; 193: 611-612.

16. Johnson N W. The role of the dental team in tobacco cessation. Eur J DentEduc 2004; 8: 18-24.

17. Raw M, McNeill A, West R. Smoking cessation guidelines for health professionals. Thorax 1998; 53: Suppl 5, Part 1.

18. Raw M, McNeill A, West R. Smoking cessation: evidence-based recommendations for the healthcare system. BrMed J 1999; 318: 182-185.

19. Watt R G, Beaglehole R H. Helping smokers stopa guide for the dental team. Health Development Agency, 2004

20. Grace M. I'll be alright, Jack. Br Dent J 2001; 191: 475

21. Department of Health. Choosing Health: making healthier choices easier. London: The Stationery Office, 2004.

22. Chestnutt I G, Binnie VI. Smoking cessation counselling - a role for the dental profession? BrDent J 1995; 179: 411-415.

23. (a) John J H, Thomas D, Richards D. Smoking cessation interventions in the Oxford region: changes in dentists' attitudes and reported practices 1996-2001. BrDent J 2003: 195: 270-275 (b) John

$\mathrm{J} H$, Yudkin P, Murphy M et al. Smoking cessation interventions for dental patients - attitudes and reported practices of dentists in the 0xford region. BrDent J 1997; 183: 359-364.

24. Allard R H B, Tobacco and oral health: attitudes and opinions of European dentists; a report of the EU working group on tobacco and oral health Int Dent J 2000; 50: 99-102.

25. Campbell HS, Sletten M, Petty T. Patient perceptions of tobacco cessation services in dental offices. J Am Dent Assoc 1999; 130: 219-226.

26. BDA Omnibus Survey, February 1999

27. BDA Omnibus Survey, March 2001.

28. Warnakulasuriya K A, Johnson N W. Dentists and oral cancer prevention in the UK: opinions, attitudes and practices to screening for mucosal lesions and to counselling patients on tobacco and alcohol use: baseline data from 1991. Oral Dis 1999; 5: 10-14

29. Prescribing arrangements for dentists. BDANews 2005; 18: 3 .

30. Warnakulasuriya S. Effectiveness of tobacco counselling in the dental office. J Dent Educ 2002; 66: 1079-1087.

31. Smith SE, Warnakulasuriya KAAS, Feyerabend C et al. A smoking cessation programme conducted through dental practices in the UK. BrDent J 1998; 185: 299-30.

32. West R, McNeill A, Raw M. Smokeless tobacco cessation guidelines for health professionals in England. Br Dent J 2004; 196: 611-618. 